\title{
What evidence exists on ecotechnologies for recycling carbon and nutrients from domestic wastewater? A systematic map
}

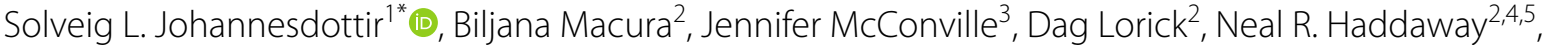 \\ Agnieszka Karczmarczyk ${ }^{6}$, Filippa Ek ${ }^{2}$, Mikołaj Piniewski ${ }^{7}$, Marta Księżniak ${ }^{8}$ and Paweł Osuch ${ }^{7}$
}

\begin{abstract}
Background: Eutrophication of the Baltic Sea, and many other water bodies, is partly the result of point-source emissions of nutrients and carbon from wastewater. At the same time, nitrogen and phosphorus planetary boundaries have been breached. There is a need for more efficient resource management, including the recovery and reuse of nutrients and carbon in waste. The aim of this paper is to collate evidence on ecotechnologies intended for use in the wastewater sector globally to facilitate the recovery or reuse of carbon and/or nutrients.

Methods: Searches were performed on literature published between 2013 and 2017 and in 5 bibliographic databases, 1 search engine, and 38 specialist websites. Database searches were performed in English. Searches in specialist websites were also performed in Finnish, Polish and Swedish. There was no geographical limitation. Screening was conducted at title and abstract level, and on full texts. Apart from bibliographical information, we extracted information on ecotechnology type, intervention, details of the recovery or reuse, the type of wastewater stream to which the ecotechnology is applied, the study location, type and design. Prior to screening and coding, we conducted consistency checks amongst reviewers. We generated a searchable database of coded studies. Findings were synthesised narratively and visualised in a geographical information system (i.e. an evidence atlas). We identified a series of knowledge gaps and clusters that warrant further research.
\end{abstract}

Results: The search resulted in 4024 records, out of which 413 articles were retained after the screening process. In addition, 35 pre-screened studies from the specialist website searches were added. Together, these 448 articles contained 474 individual studies of 28 types of ecotechnologies. A combination of ecotechnologies (16.7\%), followed by microalgae cultivation (14.1\%) were the most frequent ecotechnologies in the evidence base. Ecotechnologies for recovery composed $72.6 \%$ of the evidence base. The most common wastewater streams for recovery were mixed wastewater and sludge (73.8\%). There was a relative lack of studies on recovery from source-separated wastewater. The most common type of recovery was energy (27.3\%), followed by simultaneous recovery of nitrogen and phosphorus (22.1\%). Reuse of recovered substances was described in $22.8 \%$ of the studies. The most common type of reuse was of nitrogen and phosphorus (57.4\%), followed by joint reuse of organic carbon, nitrogen and phosphorus (35.2\%). Reuse ecotechnologies were mostly focused on the use of wastewater for irrigation or reuse of biosolids, and not on the nutrients that had been extracted through e.g. precipitation of struvite. In 22 studies both recovery and reuse were described. In total, 60 different study countries were reported in the evidence base, and the most common study location was China.

\footnotetext{
*Correspondence: solveig.johannesdottir@ri.se

${ }^{1}$ RISE Research Institutes of Sweden, Ultunaallén 4, Uppsala, Sweden

Full list of author information is available at the end of the article
}

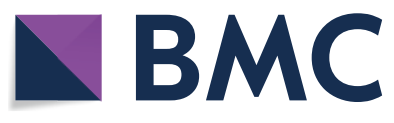

(c) The Author(s) 2020. This article is licensed under a Creative Commons Attribution 4.0 International License, which permits use, sharing, adaptation, distribution and reproduction in any medium or format, as long as you give appropriate credit to the original author(s) and the source, provide a link to the Creative Commons licence, and indicate if changes were made. The images or other third party material in this article are included in the article's Creative Commons licence, unless indicated otherwise in a credit line to the material. If material is not included in the article's Creative Commons licence and your intended use is not permitted by statutory regulation or exceeds the permitted use, you will need to obtain permission directly from the copyright holder. To view a copy of this licence, visit http://creativeco mmons.org/licenses/by/4.0/. The Creative Commons Public Domain Dedication waiver (http://creativecommons.org/publicdomain/ zero/1.0/) applies to the data made available in this article, unless otherwise stated in a credit line to the data. 
Conclusions: We found substantial evidence for the recovery and reuse of nutrients and carbon from wastewater sources. The relative abundance of studies where substances are recovered compared to studies where they are reused, suggests a knowledge gap on reuse of recovered nutrients and carbon. The majority of studies on reuse were on irrigation with treated wastewater or reuse of biosolids, and not on reuse of extracted nutrients such as struvite.

Keywords: Circular economy, Energy recovery, Fertiliser, Nutrient reuse, Resource recovery, Sewage, Wastewater treatment

\section{Background}

The ecological status of the Baltic Sea is poor and affected by eutrophication. The primary cause of eutrophication is increased loading of inorganic nutrients and organic matter from terrestrial sources which increases primary production [1] mainly as algal growth. Because the Baltic Sea has a large catchment in relation to its volume of water and a long renewal time, it is particularly vulnerable to waterborne nutrient loadings. Despite measures to decrease emissions, the spatial extent of open water eutrophication in the Baltic Sea has increased in recent years [2]. The main source of nutrients that causes eutrophication in the Baltic sea is agriculture, through so called diffuse emissions, followed by municipal wastewater treatment plants (WWTPs), through so called point sources [3]. The Shared socio-economic pathways (SSPs), recently extended for the Baltic Sea region [4] assume a wide range of future developments in drivers affecting nutrient emissions. Both diffuse and point emission pathways are projected to remain high under climate change and socio-economic change scenarios for the Baltic Sea Basin [5].

Humans can be safely sustained by the Earth systems if both nitrogen $(\mathrm{N})$ and phosphorus $(\mathrm{P})$ biogeochemical cycles are kept within planetary boundaries [6]. Human interference has caused the nitrogen cycle to breach its threshold, and fixation of $\mathrm{N}$ from the atmosphere to produce fertilisers should be reduced if we are to avoid further imbalance of the $\mathrm{N}$ cycle [6,7]. Additionally, the production of $\mathrm{N}$ fertiliser is highly energy consuming and is responsible for $5 \%$ of the global use of natural gas [8]. $\mathrm{P}$ is naturally occurring in the Earths' crust and is a nonrenewable resource that is unevenly distributed globally. The reserves of P, i.e. deposits of high-quality ore, are expected to deplete within a few hundred years [9]. The European Commission has identified $\mathrm{P}$ as critical raw materials with high economic importance and supplyrisk [10].

Municipal wastewater contains wastewater from domestic sources (e.g. excreta, flush water, washing water) and potentially industrial wastes and/or stormwater. Modern wastewater treatment plants (WWTP) are generally designed to remove solids, organic carbon (C) and other contaminants from wastewater. Many WWTPs have added tertiary treatment units to remove $\mathrm{N}$ and $\mathrm{P}$ in order to reduce the risk for eutrophication in receiving waters. Tertiary technologies originally focused on the removal of nutrients from effluent flows, either through denitrification of $\mathrm{N}$ to the atmosphere or capture and disposal of the nutrients in the sludge. However, since the early 2000s there has been increasing focus on the capture of nutrients for resource recovery [11, 12]. The potential of nutrient reuse as an agricultural fertilizer is significant [9]. For example, based on data for the year 2009 , the P contained in the excreta of the whole human population could satisfy $22 \%$ of global P demand [13]. In addition, nutrient recovery can be combined with water and energy recovery for even greater benefits. Cornejo et al. found that by integrating recovery of water, nutrients and energy, the eutrophication potential from wastewater treatment could decrease by $18 \%$ and the carbon footprint by $34 \%$ when treating wastewater from 100,000 people [14]. Apart from N and P, fertilizers and soil amendments derived from wastewater can supply soils with organic carbon (C). Organic carbon could potentially improve soil structure and counteract climate change through carbon sequestration [30].

(Re)using resources extracted from waste is central for a circular economy [16]. A transition towards circular flows of resources has entered the wastewater sector where the focus on simple removal of nutrients and $\mathrm{C}$ from waste streams has started to shift to resource recovery practices $[11,17]$. Modern WWTP could provide multiple benefits to society if they adopted resource recovery technologies [18]. There are numerous technological solutions to recover nutrients, energy and other resources from wastewater, and there is a growing interest in applying such solutions [11]. However, to our knowledge, there are no systematic and comprehensive efforts to collate current evidence on ecotechnologies to recover nutrients and $\mathrm{C}$ from wastewater sources, or to reuse of recovered $\mathrm{C}$ or nutrients globally. Although, there have been some comprehensive efforts to collate evidence (see for example [19] review on recycling human excreta) there is no systematic evidence synthesis on the subject that includes a wide set of ecotechnologies applicable across wide range of contexts. With this systematic map we aimed at closing this synthesis gap 
and we collated evidence on ecotechnologies used in the wastewater sector globally to facilitate the recovery or reuse of $\mathrm{C}$ and/or nutrients.

This systematic map was conducted within the BONUS RETURN project that uses the term "ecotechnology" defined as "human interventions in social-ecological systems in the form of practices and/or biological, physical, and chemical processes designed to minimise harm to the environment and provide services of value to society" [20].

\section{Stakeholder engagement}

The topic for this systematic map was initially proposed by the research funder BONUS (https://www.bonus portal.org). The scope of the project was then refined through expert discussions as part of the process of drafting an application in response to the call by the research funder. Once the funding was received, a diverse group of stakeholders were involved in discussions of the scope and search strategy for the map. The stakeholder group consisted of the broader BONUS RETURN project (https ://www.bonusreturn.eu) consortium members and project's case study representatives, including methodological experts on systematic maps and reviews, as well as experts in resource recovery technologies for waste and wastewater.

\section{Objective of the review}

The primary question for this systematic map is: What ecotechnologies exist in the recent research literature for the recovery or reuse of carbon, phosphorus and nitrogen from municipal and domestic wastewater systems globally? Since many wastewater technologies are not dependent on the climate zone, we have not restricted the study geographically. This map was conducted with the purpose to map research that has been done before 2017 which is when the project BONUS RETURN started.

\section{Definitions of the question components Population(s)}

Municipal wastewater systems, including systems for treatment and disposal of wastewater fractions and wastewater-derived residues and products such as digestate, effluent water, etc. The wastewater fractions considered are blackwater (i.e. urine, faeces and flush water), greywater (i.e. wastewater from sinks, baths, washers etc.), mixed wastewater (i.e. blackwater and greywater mixed), urine, sludge reject water (i.e. liquid separated from anaerobically digested sludge) and other fractions such as faecal sludge. Both municipal and domestic onsite systems, as well as co-treatment of wastewater with other organic wastes were considered. No industrial or agricultural wastewater systems were considered. $\mathrm{C}$ and nutrient recycling from agricultural sources have been addressed in a related map [21].

\section{Intervention(s)}

Any practice undertaken for the purposes of recovering and/or reusing carbon and/or nutrients in the wastewater management process including wastewater, sewage sludge, human urine etc., including the recovery of $\mathrm{C}$ in the form of energy. Ecotechnologies for recovery include the extraction or capture of the nutrients and/or $\mathrm{C}$, through e.g. nutrient adsorption or bioenergy production. Reuse refers to a further use of the recovered nutrients and/or C, for example through the application of sludge or effluents to agricultural fields as fertilizers.

\section{Outcome(s)}

Described recovery or reuse of $\mathrm{C}, \mathrm{N}$ and $\mathrm{P}$ from the wastewater management process. Energy recovery was also included as it was considered as a form of carbon recovery, since the chemical energy stored in carbon bonds in organic matter is utilized (for example by anaerobic digestion). However, reuse of recovered energy (such as using biogas for fuel) was not considered since the use of different forms of energy was outside of the scope of this map.

\section{Study type(s)}

Experimental or observational studies on N, P and/or C recovery and/or reuse. Literature reviews and commentary papers were excluded.

\section{Methods}

This systematic map was conducted according to the previously published protocol [22] and it followed the Collaboration for Environmental Evidence guidelines and standards for evidence synthesis in environmental management [23]. The map conforms to Reporting standards for systematic evidence syntheses (ROSES) [24] (see Additional file 1).

\section{Deviations from the protocol}

We have made changes to search strategy and data coding. Specifically, we have added one more literature source and made minor changes to the coding. All the deviations from the protocol are detailed in respective sections.

\section{Search for articles}

Due to the ongoing paradigm shift in the wastewater sector towards resource recovery, we were primarily interested in studies published in recent years. Additionally, this map was conducted for the purposes of the BONUS RETURN project which started in 2017. The purpose was 
to map the research that has been done before the project commenced. Thus, searches were restricted to the literature published in the period between 2013 and 2017. Search details are further described below, and search results are in Additional file 2.

\section{Bibliographic databases}

Searches for evidence were performed in the following bibliographic databases:

1. Scopus

2. Web of Science Core Collection (consisting of the following indexes: SCI-EXPANDED, SSCI, A\&HCI, CPCI-S, CPCI-SSH, and ESCI)

3. Electronic Theses Online Service (eThOS)

4. Digital Access to Research Theses (DART)

5. Directory of Open Access Journals (DOAJ)

Searches were performed using English language search terms across all bibliographic databases with subscriptions from the Warsaw University of Life Sciences (all search details including dates are in Additional file 2). The following search string was used in bibliographic databases:

("organic carbon" OR DOC OR "organic C" OR "organic matter" OR nutrient" OR nitrogen OR nitrate OR nitrite OR ammoni* OR phosphorus OR phosphate) AND (wastewater OR "waste water" OR "storm water" OR stormwater OR blackwater OR "black water" OR greywater OR "grey water" OR graywater OR "gray water" OR sludge OR septage OR sewage OR "organic waste" " OR "septic sludge" OR sewerage" OR digestate* OR "toilet waste") AND (return OR recovery OR recover OR conversion OR convert OR circulate OR circular OR reuse OR recycle) [shown as formatted for Web of Science].

\section{Search engines}

Searches in Google Scholar were performed in English. The first 1000 search results were extracted as citations using Publish or Perish software [25] and introduced into the duplication removal and screening workflow alongside records from bibliographic databases. Details of the search, including search terms used, can be found in Additional file 2.

\section{Specialist websites}

We applied a case study approach for searching for grey literature relevant for the Baltic Sea catchment area. Searches were performed in English, Swedish, Finnish and Polish across a suite of relevant organisational websites for ecotechnologies for the reuse of $\mathrm{C}$ and nutrients (see Additional file 2). Each website was hand-searched for relevant publications. Literature from organisational websites was screened separately for relevance before being combined with other records after the full text screening stage.

\section{Other sources}

Parallel to this review, ecotechnologies for carbon and nutrient recycling from agricultural waste streams were collated in a related systematic map that was conducted within the same BONUS RETURN project (and similar review team) [21]. This map used the same search sources, but different search strings. Records (screened at title and abstract or full text) found in one map but relevant to the other, were transferred between the maps, rescreened and deduplicated against the other map's records and included together with grey literature search results.

\section{Testing comprehensiveness}

Twenty-five studies of known relevance to the review were screened against scoping search results to examine whether searches were able to locate relevant records (see Additional file 2). If benchmark articles were not found during the exercise, search terms were examined to identify why relevant records were missed and search strings where further refined accordingly. Our final search string retrieved all the articles from the benchmark list."

\section{Assembling a library of search results}

Results of the bibliographic searching and Google Scholar were combined, and duplicates removed prior to screening. We have included only the most recent records in case of duplicates. A library of search results was assembled in a review management software (i.e. EPPI reviewer [26]).

\section{Article screening and study eligibility criteria Screening process}

Screening was done at two levels: at title and abstract (screened concurrently for efficiency) and at full text. Potentially relevant abstracts were retrieved and screened at full text, with each record being assessed by one experienced reviewer. Prior to commencing screening, consistency checking was performed with all reviewers on a subset of articles at both title and abstract and full text screening. A subset of 723 title and abstract $(20 \%$ of initial search results from Scopus, Google Scholar and Web of Science Core Collection) was independently screened by all reviewers. The level of agreement between reviewers was between 71 and $78 \%$ on title and abstract level. After clarifying all the disagreements and eligibility criteria the reviewers proceeded with the screening. Twentyfour full texts were screened for consistency checking 
(1.8\% of retrieved full texts). The agreement reached $70 \%$ after discussing and resolving disagreements. Reviewers did not author any of the studies screened or appraised for this review, and therefore no measures for procedural independence had to be taken.

\section{Eligibility criteria}

The following criteria were applied at all levels of screening:

\section{Eligible population(s)}

Wastewater systems, including systems for treatment and disposal of wastewater-derived residues and fractions such as digestate, effluent water, urine etc. Both municipal and on-site systems were included, as well as co-treatment of wastewater with other organic wastes. Industrial and agricultural wastewaters were not eligible.

\section{Eligible intervention(s)}

Any practice undertaken for the purposes of recovering and/or reusing $C$ and/or nutrients from the wastewater management process.

\section{Eligible outcome(s)}

Described recovery or reuse of $\mathrm{C}$ and/or nutrients from the wastewater management processes. $\mathrm{C}$ outcomes included: energy, methane, biogas, soil $\mathrm{C}$, soil organic $\mathrm{C}$, total $\mathrm{C}$, dissolved organic $\mathrm{C}$, and organic matter, but also chemical oxygen demand and biological oxygen demand, which are proxies for $\mathrm{C}$. Nutrient outcomes included: $\mathrm{N}$ compounds ( $\mathrm{N}$, nitrate, nitrite, ammonium) and $\mathrm{P}$ compounds (P, phosphate).

\section{Eligible study type(s)}

Observational and experimental studies on nutrient and/ or carbon recovery and/or reuse. Review articles and commentary papers were excluded.

\section{Study validity assessment}

The validity of articles was not appraised as part of this systematic map in accordance with established methodological guidance [27].

\section{Data coding strategy}

Apart from extracting bibliographical information, we coded each included study as follows:

- Ecotechnology type (coded after all ecotechnologies were identified)
- Short description of ecotechnology (as stated in the study)

- Wastewater fraction (to which the ecotechnology is applied such as blackwater, greywater, mixed wastewater, sludge, sludge reject water, urine, several inputs, other (e.g. faecal sludge))

- Resource recovered or reused (i.e. organic C, energy, $\mathrm{N}, \mathrm{P})$

- Study location (latitude, longitude)

Meta-data extraction was performed by 4 reviewers following consistency checking based on a parallel coding of 24 full texts, discussing all disagreements. Contacting authors by email with requests for missing information was not necessary, since the eligible studies reported all required information.

Initially, we planned to distinguish between 'explicit' and 'implicit' reuse. However, making this distinction proved to be very difficult because studies often lacked the necessary details to determine whether recovery was conducted with the intention of reuse. Therefore, we decided to include studies that clearly mentioned recovery with the intention of reusing the $\mathrm{C}$ or nutrients as well as studies where reuse of recovered $C$ or nutrient was described. The studies of recovery were separated from the studies of reuse by the ecotechnology categories. If the potential use of the recovered $\mathrm{C}$ or nutrients was not described, the article was excluded.

We have extracted study coordinates including either sampling locations, the location where the ecotechnology was developed, or where it was implemented. In cases where no such information was provided, the coordinates were extracted from the affiliation of the main author. In some cases when the publication was a book the affiliation of the author of the relevant chapter was used, instead of the main author of the whole book.

\section{Data mapping method}

The evidence base identified within this review was presented as a systematic map database, i.e. a searchable spreadsheet with meta-data and coding (as per the metadata extraction and coding schema presented above). We produced cross-tabulations of 2 categorical variables (also referred to as 'heat maps') to describe knowledge gaps and clusters i.e. to detail the volume of evidence (number of studies) across different combinations of variables. The cross-tabulations included: the type of ecotechnologies and the outcome(s); the type of ecotechnologies and the input substrate; the input substrate and outcome(s). We also produced an evidence atlas where studies were plotted on an interactive geographical information system (using study latitude and longitude meta-data). 


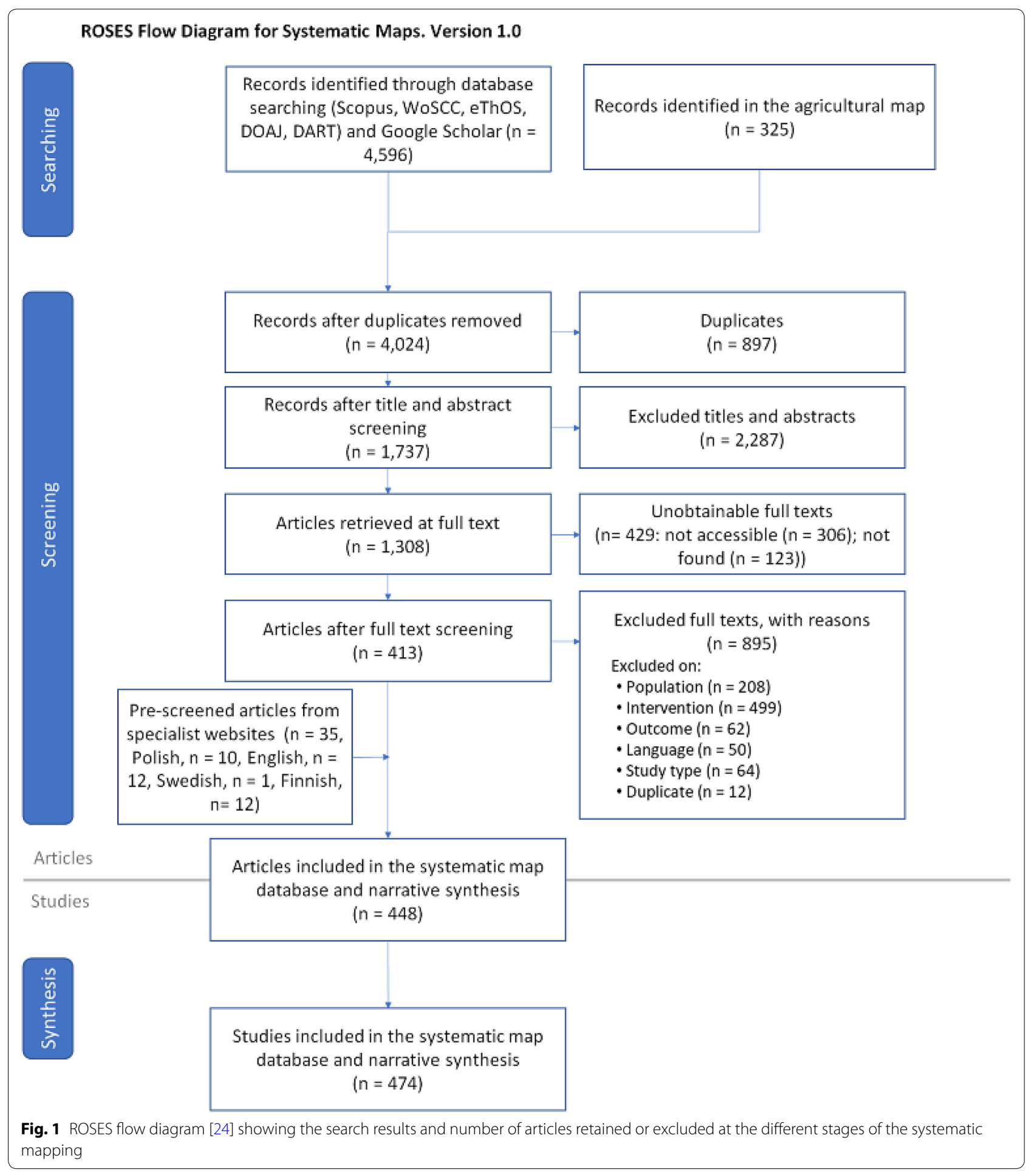

\section{Results}

\section{Review descriptive statistics}

The searches in all bibliographic databases and Google Scholar resulted in 4596 records and from the map of ecotechnologies applied to agricultural waste streams [19] 325 records were added (Fig. 1). After duplicate removal (897), a total of 4024 records were screened on title and abstract level, and 1737 records were judged as eligible for full text screening and were marked for retrieval. A list of the unobtainable articles (429) is provided in Additional file 3. Out of 1308 retrieved and screened records at full text, 415 articles were included in the systematic map database. There were 35 articles added from specialist searches and the final database 
included 450 articles. All search results, including search settings, dates and subscription information, are reported in Additional file 2. A list of all articles excluded at full text screening with reasons for exclusions is provided in Additional file 4, and a list of all included articles including meta-data and coding is provided in Additional file 5. The map database contains articles that include more than one study of ecotechnologies, i.e. if one article details several different treatment trains (e.g. separate recovery of two different products from two different waste streams). In such cases, these articles (21 in total) were split into two or more studies and coded separately. Each separate study of ecotechnology was assigned a unique study ID and is referred to as a 'study' in this map. There are in total 476 studies in the evidence base.

Figure 2 shows the number of articles in the evidence base published per year. During the years of 2013-2016 the number of articles published per year increased from 61 to 115 and 85 articles in the evidence base were published in 2017. Note that the searches for the main body of literature screening were performed in July/August 2017 (see Additional file 1) and articles published in late 2017 were therefore not included in the evidence base. Given the volume of evidence and limitations to resources, we were unable to update the searches before publication. As seen in Fig. 2, the majority of the included articles were journal articles.

\section{Evidence atlas}

We have created an evidence atlas using the EviAtlas tool [28] and it is accessible at https://www.bonusreturn.eu/ program/evidence-base-for-ecotechnologies-in-waste water-treatment/. The evidence atlas shows the locations from the studies included in the systematic map database on a cartographic map.

It is interactive and can be searched using a visual interface (see Fig. 3).

In total, 60 different countries were represented in the evidence base (see Additional file 6). The location with the most studies in the evidence database was China (16.4\%), followed by the US (8.0\%) and Spain (7.6\%). Among the European countries, apart from Spain, Poland was the most common study location (5.5\%), followed by the UK (4.6\%), the Netherlands (4.2\%) and Italy (4.0\%). The remaining 53 countries were the study location in less than $4 \%$ of the articles in the evidence base.

\section{Categories of ecotechnologies}

In the 474 studies mapped, 28 categories of ecotechnologies were identified (Fig. 4). One of these categories is 'Combination', representing studies where two or more ecotechnologies are combined for recovery or reuse. Most studies in the evidence base were focusing on recovering carbon and nutrients $(\mathrm{n}=344,72.6 \%)$ in contrast to reuse $(n=108,22.8 \%)$ in the evidence base. Some studies presented both the recovery and reuse of carbon or nutrients $(\mathrm{n}=22,4.6 \%)$ through a combination

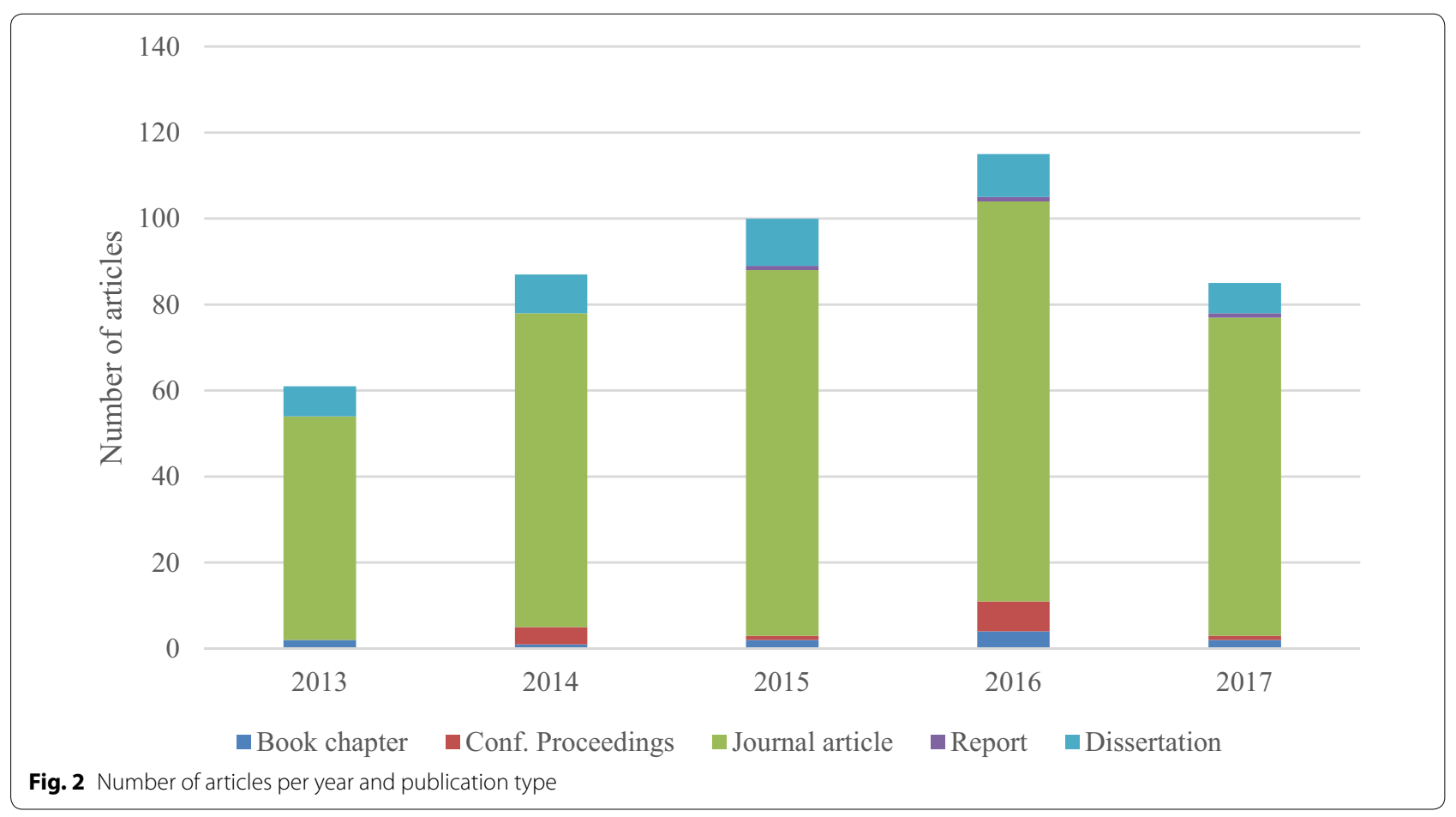




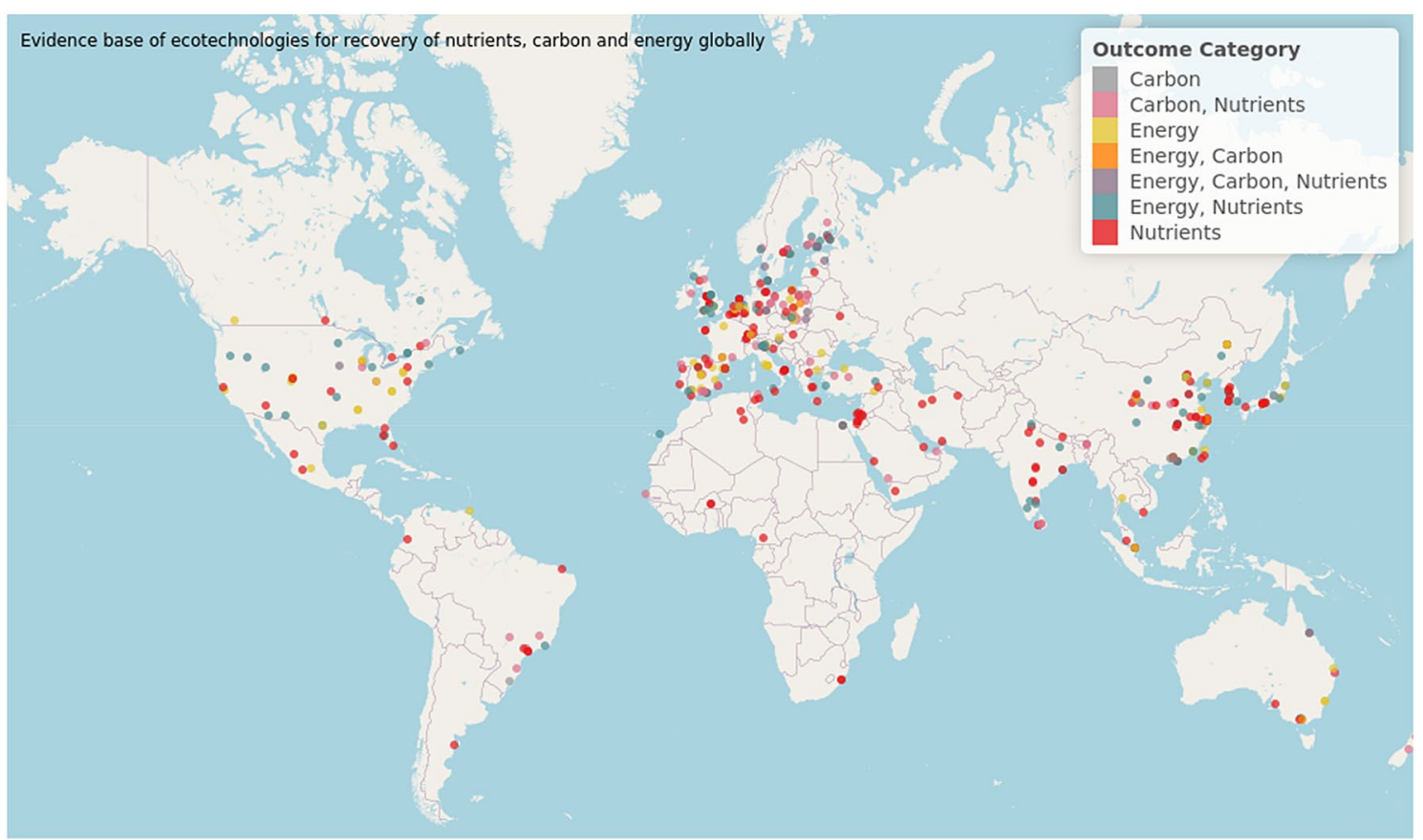

Fig. 3 Screenshot of the evidence atlas

of ecotechnologies, but most studies focused solely on either recovery or reuse. The most prevalent category of ecotechnologies in the evidence base was 'Combinations' $(\mathrm{n}=79,16.7 \%)$. This was followed by 'Microalgae cultivation' $(n=67,14.1 \%)$ and 'Irrigation with effluents' $(n=58$, $12.2 \%$ ) as the second and third most abundant. The next most frequent ecotechnologies were 'Reuse of biosolids' $(\mathrm{n}=39,8.2 \%)$ followed by 'Anaerobic digestion' ( $\mathrm{n}=36$, 7.6\%). The category "Other" includes 19 studies (4.0\%) describing ecotechnologies that do not fit in any of the other categories. The 10 categories with lowest number of studies together comprised $4.9 \%$ of the studies.

\section{Ecotechnologies and recovery}

Ecotechnology categories and the substances recovered are shown in Table 1. Note that the studies including both recovery and reuse are not included in the Tables 1 , $2,3,4$, but they are described in separate section further below. When considering recovery ecotechnologies only, microalgae cultivation was the most common $(n=67,14.1 \%)$ followed by combination $(n=59,12.0 \%)$. Energy recovery only was the most common recovery type, and specifically via microalgae cultivation, combination of technologies and anaerobic digestion. Although the recovery of energy by microalgae cultivation is often done through anaerobically digesting the algal biomass, the studies that did not describe the digestion process were not coded as anaerobic digestion (those that did are categorised as 'Combination' of ecotechnologies). The joint $\mathrm{N}$ and $\mathrm{P}$ was the second most common type of recovery, and specifically through struvite recovery (27 out of 76 studies) and microalgae cultivation (24 out of 76). This was followed by joint recovery of energy, $\mathrm{N}$ and $\mathrm{P}(\mathrm{n}=69,20.0 \%)$. Recovering only one substance (except for energy) was less common than joint recovery. The most common substance to recover singularly besides energy was $P(n=37,10.8 \%)$, followed by $N(n=13,3.8 \%)$ and organic $C(n=6,1.7 \%)$.

\section{Recovery substrate}

Out of 8 waste streams used as a recovery substrate in the evidence base (Table 2), the most common was mixed wastewater $(162,47.1 \%)$, i.e. greywater and blackwater mixed (as is commonly the case in regular sewer systems). The second most common input was sludge $(n=92,26.7 \%)$. Source-separated black- and greywater were the least common recovery substrates in the evidence base with only 4 and 2 studies, respectively. Note, however, that faecal sludge was coded as 'Other' type of input. The recovery from source-separated urine was 


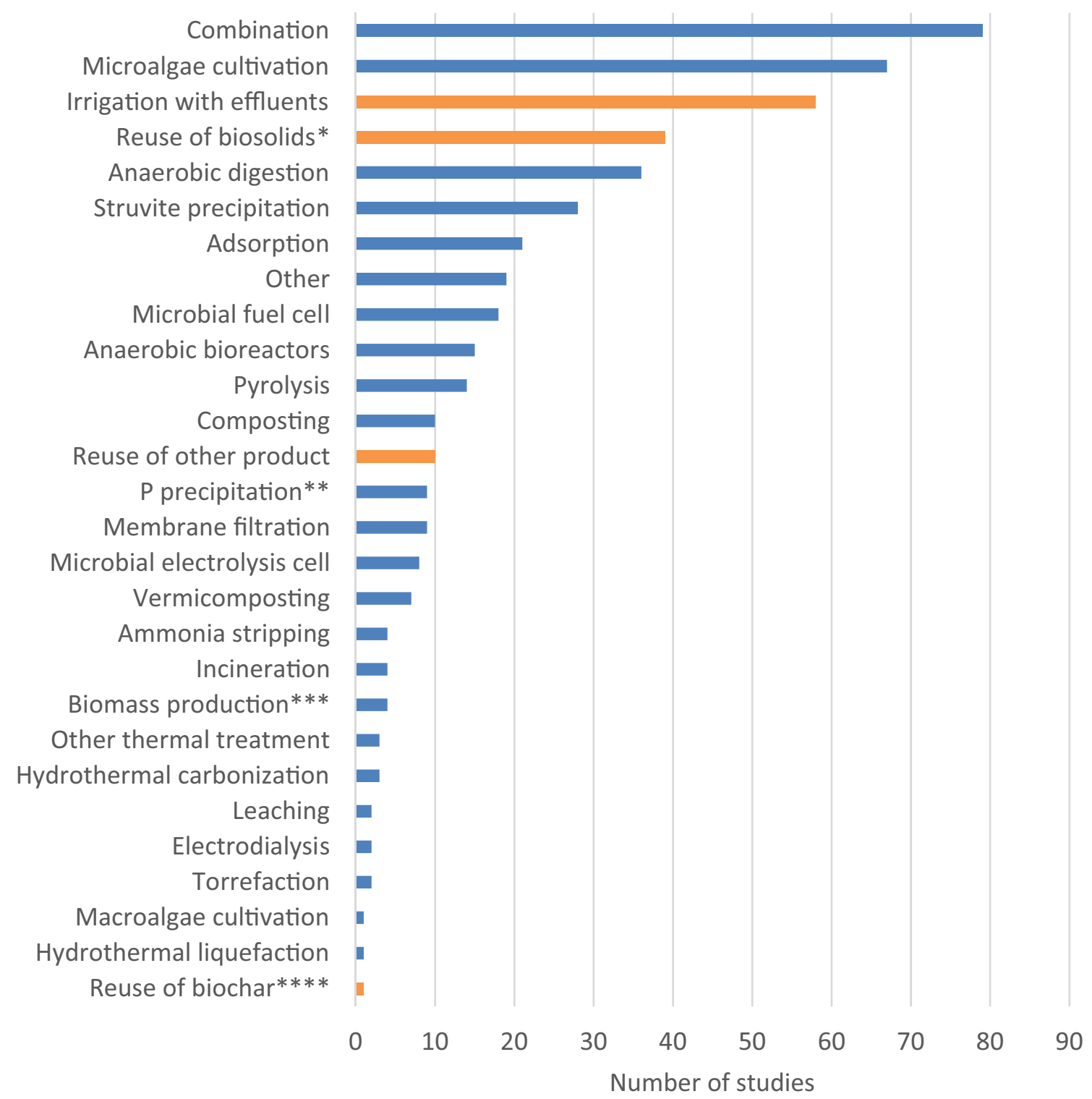

Fig. 4 The number of studies per category $(n=28)$ of ecotechnology in the evidence base $(n=474)$. Blue represents recovery ecotechnologies and orange represent reuse ecotechnologies. *biosolids/sludge/compost, ${ }^{* *}$ Other than struvite, ${ }^{* * *}$ directly in substrate other than microalgae, ****biochar/biocoal/adsorption medium

more common in the evidence base $(28,8.1 \%)$ than blackand greywater. The most common types of recovery from mixed wastewater was joint energy, P and N (49 out of 162) followed by joint $P$ and $N$ or only energy recovery (44 out of 162 for both). From sludge, the most frequent recovery was only energy (43 out of 92 studies). From urine the most frequent recovery was joint $\mathrm{P}$ and $\mathrm{N}$ (18 out of 28).

The most common waste stream studied for use in recovery was wastewater. This stream was the most often used for cultivation of microalgae (52 out of 162 studies) as well as for combination of ecotechnologies (27 out of 162 studies) (see Additional file 6). Sludge was the most frequently reported substrate used for anaerobic digestion (34 out of 92 studies) in the evidence base. Sludge reject water was most often used for struvite precipitation (9 out of 23 studies). For urine, the most frequent ecotechnology applied was struvite precipitation or relatively rare technologies (both 6 out of 28 studies), such as membrane distillation (category 'Others'). 
Table 1 Ecotechnologies identified as recovering carbon (C), energy (E), phosphorus (P) and/or nitrogen (N) $(n=344)$. Studies including both recovery and reuse are not presented $(n=22)$

\begin{tabular}{|c|c|c|c|c|c|c|c|c|c|c|c|c|c|c|}
\hline Ecotechnology & C & $\mathrm{E}$ & $\mathbf{P}$ & $N$ & $C \& E$ & $P \& N$ & $E \& P$ & $E \& N$ & $C \& P$ & $E, P \& N$ & $C, P \& N$ & $E, C \& P$ & $E, C, P \& N$ & Total \\
\hline Microalgae cultivation & & & & & & 24 & & & & 43 & & & & 67 \\
\hline Combination & & 8 & 7 & & & 8 & 4 & 3 & 1 & 21 & 2 & & 3 & 57 \\
\hline Anaerobic digestion & & 33 & & & & & & & & & 1 & & 2 & 36 \\
\hline Struvite precipitation & & & 1 & & & 27 & & & & & & & & 28 \\
\hline Adsorption & & & 14 & 4 & & 3 & & & & & & & & 21 \\
\hline Other & 2 & 3 & 1 & 2 & & 7 & & & & & 3 & & 1 & 19 \\
\hline Microbial fuel cell & & 16 & & 1 & & & & 1 & & & & & & 18 \\
\hline Anaerobic bioreactors & & 14 & & & & & & & & 1 & & & & 15 \\
\hline Pyrolysis & 2 & 4 & & & 4 & & & & & & & 2 & 2 & 14 \\
\hline Composting & & & & & & & & & & & 10 & & & 10 \\
\hline P precipitation ${ }^{\mathrm{a}}$ & & & 9 & & & & & & & & & & & 9 \\
\hline Membrane filtration & 1 & & 1 & 2 & & 5 & & & & & & & & 9 \\
\hline Microbial electrolysis cell & & 8 & & & & & & & & & & & & 8 \\
\hline Vermicomposting & & & & & & & & & & & 7 & & & 7 \\
\hline Biomass production ${ }^{b}$ & & & & & & 1 & & & & 3 & & & & 4 \\
\hline Incineration & & 3 & & & & & 1 & & & & & & & 4 \\
\hline Ammonia stripping & & & & 4 & & & & & & & & & & 4 \\
\hline Other thermal treatment & & 2 & & & & & & & & & 1 & & & 3 \\
\hline Hydrothermal carbonization & 1 & & & & & & 1 & & & 1 & & & & 3 \\
\hline Electrodialysis & & & 2 & & & & & & & & & & & 2 \\
\hline Torrefaction & & 2 & & & & & & & & & & & & 2 \\
\hline Leaching & & & 2 & & & & & & & & & & & 2 \\
\hline Hydrothermal liquefaction & & 1 & & & & & & & & & & & & 1 \\
\hline Macroalgae cultivation & & & & & & 1 & & & & & & & & 1 \\
\hline Total & 6 & 94 & 37 & 13 & 4 & 76 & 6 & 4 & 1 & 69 & 24 & 2 & 8 & 344 \\
\hline
\end{tabular}

a Other than struvite

${ }^{b}$ Directly in substrate, other than algae

Table 2 Waste streams used for recovery of $C, E, P$ and/or $N(n=344)$

\begin{tabular}{|c|c|c|c|c|c|c|c|c|c|c|c|c|c|c|}
\hline Waste stream & $C$ & $E$ & $\mathbf{P}$ & $\mathrm{N}$ & $C \& E$ & $P \& N$ & $E \& P$ & $E \& N$ & $C \& P$ & $E, P \& N$ & $C, P \& N$ & $E, C \& P$ & $E, C, P \& N$ & Total \\
\hline Mixed wastewater & 2 & 44 & 18 & & & 44 & 1 & 2 & & 49 & 1 & & 1 & 162 \\
\hline Sludge & 3 & 43 & 6 & & 4 & 1 & 4 & 2 & & 5 & 18 & 2 & 4 & 92 \\
\hline Urine & & 1 & 1 & 6 & & 18 & & & & 2 & & & & 28 \\
\hline Sludge liquid phase & 1 & & 3 & 2 & & 11 & & & & 6 & & & & 23 \\
\hline Several inputs & & 2 & 3 & 4 & & 1 & 1 & & 1 & 6 & 1 & & 1 & 20 \\
\hline Other & & 4 & 6 & 1 & & & & & & & 2 & & & 13 \\
\hline Blackwater & & & & & & & & & & & 2 & & 2 & 4 \\
\hline Greywater & & & & & & 1 & & & & 1 & & & & 2 \\
\hline Total & 6 & 94 & 37 & 13 & 4 & 76 & 6 & 4 & 1 & 69 & 24 & 2 & 8 & 344 \\
\hline
\end{tabular}

Studies including both recovery and reuse are not presented $(n=22)$

\section{Ecotechnologies and reuse}

Only 108 of the studied ecotechnologies $(22.7 \%)$ in the evidence base solely involved the reuse of recovered substances including $\mathrm{C}, \mathrm{P}$ and $\mathrm{N}$ (Table 3). The reuse ecotechnologies identified in the evidence base were irrigation with effluents, reuse of biosolids/sludge/compost, reuse of biochar/biocoal/adsorption medium and reuse of other product (e.g. struvite and sewage sludge ash). The majority of ecotechnologies for reuse were irrigation with effluents $(n=58,53.7 \%)$ and reuse of 
Table 3 Ecotechnologies identified for reuse of $\mathrm{C}, \mathrm{P}$ and/ or $\mathbf{N}(n=108)$

\begin{tabular}{|c|c|c|c|c|c|}
\hline Ecotechnology & C & $\mathbf{P}$ & $P \& N$ & $C, P \& N$ & Total \\
\hline Irrigation with effluents & & & 57 & 1 & 58 \\
\hline Reuse of biosolids ${ }^{\mathrm{a}}$ & 3 & & & 36 & 39 \\
\hline Reuse of other product & 1 & 3 & 5 & 1 & 10 \\
\hline $\begin{array}{c}\text { Reuse of biochar }{ }^{\mathrm{b}} \text {, biocoal } \\
\text { or adsorption medium }\end{array}$ & 1 & & & & 1 \\
\hline Total & 5 & 3 & 62 & 38 & 108 \\
\hline
\end{tabular}

Studies including both recovery and reuse are not presented $(n=22)$

a /sludge/compost

b /biocoal/adsorption medium

biosolids ( $n=39,36.1 \%)$. Reuse of nutrients that had been extracted, for example, by precipitation of struvite were not common in the evidence base, i.e. 'Reuse of other product' ( $\mathrm{n}=10,9.3 \%)$. Joint $\mathrm{P}$ and $\mathrm{N}$ reuse was the most common, followed by ecotechnologies for joint $\mathrm{C}$, $\mathrm{N}$ and P reuse (57.4\% and $35.2 \%$, respectively).

\section{Combinations of ecotechnologies}

Amongst the 79 studies of combinations of ecotechnologies, 45 different combinations were identified (see Additional file 6). Thirty-three of the different combinations appeared in only one study. The combinations studied in more than 1 study (12 combinations) and the substances recovered or reused is shown in Table 4. A table showing the output of every combination is shown in Additional file 6 . The most prevalent combination of ecotechnologies in the database was microalgae cultivation followed by anaerobic digestion of the algal biomass $(n=11$, 13.9\%) (Table 4). The second most prevalent combination was anaerobic digestion followed by microalgae cultivation in the liquid separated from the digestate $(n=7$, 8.9\%). Through microalgae cultivation and anaerobic digestion of the algal biomass, energy is recovered as well as $\mathrm{N}$ and $\mathrm{P}$ (incorporated into the biomass). The same substances are recovered by combining the ecotechnologies in the opposite order, as well as hydrothermal liquefaction of the algal biomass. Reusing biochar or nutrient enriched adsorption medium was as common in the evidence base as recovering $\mathrm{P}$ from ashes after incineration of a waste stream (typically sludge) $(n=3,3.8 \%)$.

\section{Studies of both recovery and reuse}

Only 22 studies in the evidence base (4.6\%) described both recovery and reuse of energy (only recovery), $\mathrm{C}, \mathrm{P}$ and/or N. Amongst this subset, the most common waste stream was mixed wastewater and sludge (Table 5). The most common substance to recover or reuse was joint $\mathrm{P}$ and $\mathrm{N}$.

\section{Limitations of the map}

The limitations of the map may originate from: (1) the mapping methodology; and (2) bias in the pool of studies found. We will address both types of limitations consecutively.

Our search string included 3 substrings with search terms on (1) nutrients, (2) types of waste sources and (3) general reuse and recovery terms. We have not used any search terms connected to specific ecotechnologies or to types of reuse and recovery, which was a trade-off that we

Table 4 The 12 most common combinations of ecotechnologies and the recovered or reused substance(s) $(n=45)$

\begin{tabular}{|c|c|c|c|c|c|c|c|c|c|c|c|c|}
\hline Combination & E & $\mathbf{P}$ & $\mathbf{N}$ & $C \& E$ & $P \& N$ & $E \& P$ & $C \& P$ & $E, P \& N$ & $C, P \& N$ & $\mathrm{E}, \mathrm{C} \& \mathrm{P}$ & $E, C, P \& N$ & Total \\
\hline Microalgae cultivation -> Anaerobic digestion & & & & & & & & 11 & & & & 11 \\
\hline Anaerobic digestion -> Microalgae cultivation & & & & & & & & 6 & & & 1 & 7 \\
\hline Microalgae cultivation -> HTL ${ }^{a}$ & & & & & & & & 4 & & & & 4 \\
\hline Adsorption -> Reuse of biochar ${ }^{b}$ & & 2 & 1 & & 1 & & & & & & & 4 \\
\hline Pyrolysis -> Reuse of biochar ${ }^{b}$ & & & & 1 & & & & & & 3 & & 4 \\
\hline Incineration -> Thermal ash recovery & & 3 & & & & 1 & & & & & & 4 \\
\hline Adsorption -> Microalgae cultivation & & 2 & & & 1 & & & & & & & 3 \\
\hline Composting -> Reuse of biosolids ${ }^{c}$ & & & & & & & & & 3 & & & 3 \\
\hline Adsorption -> Struvite precipitation & & & & & 2 & & & & & & & 2 \\
\hline Struvite precipitation -> Microbial fuel cell & & & & & 1 & & & 1 & & & & 2 \\
\hline Pyrolysis -> Adsorption & & & & & & & 1 & & 1 & & & 2 \\
\hline Membrane filtration -> Microbial fuel cell & 2 & & & & & & & & & & & 2 \\
\hline
\end{tabular}

Total number of studies of combinations is 79

a Hydrothermal liquefaction

b /biocoal/adsorption medium

c/sludge/compost 
Table 5 Waste stream and recovered or reused substance(s) in the studies where both recovery and reuse were studied $(n=22)$

\begin{tabular}{|c|c|c|c|c|c|c|c|c|c|}
\hline Waste stream & $\mathbf{P}$ & $\mathbf{N}$ & $C \& E$ & $P \& N$ & $E, P \& N$ & $C, P \& N$ & $E, C \& P$ & $E, C, P \& N$ & Total \\
\hline Mixed wastewater & 1 & 1 & & 3 & 1 & & & 2 & 8 \\
\hline Sludge & & & 1 & & & 2 & 4 & 1 & 8 \\
\hline Urine & & & & 2 & & & & & 2 \\
\hline Several inputs & & & 1 & 1 & & & & & 2 \\
\hline Other & & & & & & 1 & & & 1 \\
\hline Sludge liquid phase & 1 & & & & & & & & 1 \\
\hline Total & 2 & 1 & 2 & 6 & 1 & 3 & 4 & 3 & 22 \\
\hline
\end{tabular}

employed to remain as inclusive as possible. This, however, may have resulted in some relevant ecotechnologies not being picked up by our searches. Additionally, 25\% of articles included at title and abstract screening had irretrievable full texts.

Even though the searches in bibliographic databases had no geographical restrictions, we have limited grey sources to organisations based in European countries, with the one exception (US EPA) (see Additional file 2). The number of relevant results from grey literature sources was very small in relation to the scientific literature identified and we expect the same trend if the grey literature searches were extended. Nonetheless, future work could expand the map to include searches in more languages and more varied grey literature sources to avoid geographical bias. Furthermore, the searches were limited to the literature published between 2013 and 2017 , but future reviews could easily build on this map and include both older and more recent literature.

Each study has been coded for a type of the recovered or reused substance (N, P, C or energy), but the amount of a recovered or reused substance was not recorded. The recovery or reuse of one substance (for example $\mathrm{N}$ ) was indicated explicitly, while the recovery or reuse of other substances (for example P) in the same study might have only be implied. The distinction between explicitly stated reuse of a recovered product and potential or implicit reuse were not captured in the evidence base, but all products were coded regardless of this. Given that authors were often unclear if there was a real potential for nutrient recovery and reuse, we relied on the expertise in our review team. Interestingly, the majority of ineligible studies $(55.8 \%)$ were excluded because they were mostly about the removal of $\mathrm{C}$ and nutrients, without reuse of them, as is standard practice for treating wastewater for release into the environment.

\section{Conclusions}

Implication for policy/management

This study is the first systematic mapping performed on the topic of $\mathrm{C}$ and nutrient recovery and reuse from domestic wastewater and can aid decision-makers to navigate the vast body of literature existing on resource recovery from municipal wastewater. Although we found substantial amount of literature on different circular solutions (474 studies in total), the evidence base is much larger for ecotechnologies for carbon and nutrients recovery than for reuse. Our findings suggest that there is a need for policies encouraging reuse or more research funding to investigate the (efficiency of) reuse of carbon and nutrients from wastewater, including risks and benefits of reuse.

Additionally, identified ecotechnologies for nutrient and $C$ reuse were mostly focused on the use of wastewater for irrigation or biosolids as organic fertilizers or soil amendments, and not on the nutrients that have been extracted through e.g. precipitation of struvite. This indicates a knowledge gap in the use of extracted $\mathrm{C}, \mathrm{N}$ and $\mathrm{P}$ in agriculture as opposed to the use of biosolids as fertilizers. Current policy trends in Europe are moving towards decreased use of sludge in agriculture [29, 30] which suggests there is a potential need for a legal framework encouraging reuse of recycled nutrients by other means than sludge application. Additionally, by returning captured $\mathrm{C}$ to soils can lead to $\mathrm{C}$ sequestration and negative greenhouse gas emissions [15]. Applying $C$ recovered from wastewater, e.g. as sludge, is one way of returning $\mathrm{C}$ to soils. Given the significant threat of climate change and the need to reduce greenhouse gas emissions, the potential for $\mathrm{C}$ sequestration from wastewater sources should be relevant further assessed to inform policies. 


\section{Implications for research}

- We hope this systematic map and associated evidence atlas could provide useful tool for researchers interested in carbon and nutrient recovery from domestic wastewater to identify interesting topics for future primary research or reviews. We found several knowledge gaps that future research could address: Reusing $\mathrm{C}$ or nutrients in wastewater sector (including quality aspects, fertilizing performance and broader life-cycle assessments).

- Effectiveness and implementation of ecotechnologies for recovery other than microalgae cultivation, anaerobic digestion and struvite precipitation. BONUS RETURN project is already addressing recovery of nutrients by ammonia stripping [31].

- Recovery from waste streams other than well-studied mixed wastewater and sludge.

- Reuse potential by other means than well-studied irrigation with effluents or sludge application, such as reuse of nutrients extracted by struvite precipitation. BONUS RETURN project is already addressing one of the identified synthesis gaps on reuse of extracted nutrients from struvite precipitation and ammonia stripping [31].

- More primary research on ecotechnologies for recovery or reuse from wastewater conducted in Africa, South America and Asia (apart from China) potentially needed. These locations are also where large areas are lacking sewer systems today and thus lack mixed wastewater, and sewage sludge. Research in these locations could therefore address two of the knowledge gaps stated here.

- Studies including the aspect of technical maturity of ecotechnologies.

\section{Knowledge clusters identified where there is a lot of evidence to conduct a synthesis include}

- Effectiveness and implementation of ecotechnologies for recovery of carbon and nutrients by microalgae cultivation, anaerobic digestion or struvite precipitation. BONUS RETURN project is already addressing recovery of nutrients by struvite precipitation [31].

- Reuse of carbon and nutrients through irrigation with treated effluents and sludge.

- Implementation of ecotechnologies for recovery and reuse from wastewater in developed countries, where there is an extensive wastewater infrastructure in place.
Furthermore, this map could be extended to:

1. Identify the most efficient processes for recovery and reuse of each resource considered.

2. Identify co-benefits associated with application of ecotechnologies to assess their economic, technical and social feasibility (and provide policy guidance).

3. Collate studies that map the evidence over a broader time scale which could give a better picture of the development trends within the area of recovering and reuse carbon and nutrients from municipal wastewater.

If all this is done, we could have a more comprehensive decision support tool for circular solutions in the wastewater sector globally. Decision support tools of this kind facilitate evidence-based policies and sustainable development.

\section{Supplementary information}

Supplementary information accompanies this paper at https://doi. org/10.1186/s13750-020-00207-7.

Additional file 1. ROSES form for systematic maps.

Additional file 2. Search results.

Additional file 3. List of unretrievable articles.

Additional file 4. List of articles excluded at full text screening with reasons for exclusion.

Additional file 5. Systematic map evidence database.

Additional file 6. Additional tables.

\section{Acknowledgements}

We thank the BONUS Secretariat for their generous funding. We are grateful for the support from the BONUS RETURN consortium and project partners. We are grateful for the work performed by the review team, apart from the coauthors, including Karolin Andersson, Sirkka Tattari and Jari Koskiaho.

\section{Authors' contributions. \\ $S L J, B M$ and JM wrote the initial version of the manuscript. All authors read and approved the final manuscript.}

\section{Funding}

This systematic map was conducted as part of BONUS RETURN project. BONUS RETURN project is supported by BONUS (Art 185), funded jointly by the EU and Swedish Foundation for Strategic Environmental Research FORMAS (project\#: 2016-01076), Sweden's innovation agency VINNOVA, Academy of Finland and National Centre for Research and Development in Poland.

\section{Availability of data and materials}

The datasets supporting the conclusions of this article are included within the article and its additional files.

Ethics approval and consent to participate

Not applicable.

Consent for publication

Not applicable. 


\section{Competing interests}

The authors declare they have no competing interests.

\section{Author details}

${ }^{1}$ RISE Research Institutes of Sweden, Ultunaallén 4, Uppsala, Sweden.

2 Stockholm Environment Institute, Linnégatan 87D, Stockholm, Sweden.

3 Department of Energy and Technology, Swedish University of Agricultural Sciences, Box 7032, 75007 Uppsala, Sweden. ${ }^{4}$ Africa Centre for Evidence, University of Johannesburg, Johannesburg, South Africa. ${ }^{5}$ Mercator Research Institute on Global Commons and Climate Change, Berlin, Germany. ${ }^{6}$ Department of Environmental Development, Warsaw University of Life Sciences, Nowoursynowska 166, 02-787 Warsaw, Poland. ${ }^{7}$ Department of Hydrology, Meteorology and Water Resources, Warsaw University of Life Sciences, Nowoursynowska 166, 02-787 Warsaw, Poland. ${ }^{8}$ Department of Remote Sensing and Environmental Assessment, Warsaw University of Life Sciences, Nowoursynowska 166, 02-787 Warsaw, Poland.

Received: 22 April 2020 Accepted: 17 September 2020 Published online: 06 October 2020

\section{References}

1. HELCOM. Ecosystem health of the Baltic Sea 2003-2007: HELCOM Initial Holistic Assessment. Baltic Sea Environ Proceed. 2010;122:63.

2. Fleming-Lehtinen V, Andersen JH, Carstensen J, Łysiak-Pastuszak E, Murray C, Pyhälä M, et al. Recent developments in assessment methodology reveal that the Baltic Sea eutrophication problem is expanding. Ecol Ind. 2015:48:380-8.

3. HELCOM. Sources and Pathways for Nutrients to the Baltic Sea (PLC-6). Baltic Sea Environment Proceedings No 153. 2018.

4. Zandersen M, Hyytiäinen K, Meier HEM, Tomczak MT, Bauer B, Haapasaari $P E$, et al. Shared socio-economic pathways extended for the Baltic Sea: exploring long-term environmental problems. Reg Environ Change. 2019:19:1073-86

5. Bartosova A, Capell R, Olesen JE, Jabloun M, Refsgaard JC, Donnelly $C$, et al. Future socioeconomic conditions may have a larger impact than climate change on nutrient loads to the Baltic Sea. Ambio. 2019:48:1325-36.

6. Rockström J, Steffen W, Noone K, Persson Å, Chapin lii FS, Lambin EF, et al. A safe operating space for humanity. Nature. 2009;461:472.

7. Steffen W, Richardson K, Rockström J, Cornell SE, Fetzer I, Bennett EM, et al. Planetary boundaries: Guiding human development on a changing planet. Science. 2015;347. http://science.sciencemag.org/content/ sci/347/6223/1259855.full.pdf.

8. Razon LF. Reactive nitrogen: A perspective on its global impact and prospects for its sustainable production. $2018 \mathrm{https}$ //pubag.nal.usda. gov/catalog/6042076 Accessed 16 Mar 2020.

9. Dawson CJ, Hilton J. Fertiliser availability in a resource-limited world production and recycling of nitrogen and phosphorus. Food Policy. 2011:36:14-22.

10. European Commission. on the 2017 list of Critical Raw Materials for the EU. 2017.

11. Guest JS, Skerlos SJ, Barnard JL, Beck MB, Daigger GT, Hilger H, et al. A new planning and design paradigm to achieve sustainable resource recovery from wastewater. Environ Sci Technol. 2009;43:6126-30.

12. Larsen TA, Alder AC, Eggen RIL, Maurer M, Lienert J. Source separation: will we see a paradigm shift in wastewater handling. Environ Sci Technol. 2009:43:6121-5.

13. Mihelcic JR, Fry LM, Shaw R. Global potential of phosphorus recovery from human urine and feces. Chemosphere. 2011:84:832-9.
14. Cornejo PK, Zhang Q, Mihelcic JR. How Does Scale of Implementation Impact the Environmental Sustainability of Wastewater Treatment Integrated with Resource Recovery? Environ Sci Technol. 2016;50:6680-9.

15. Pitombo LM, do Carmo JB, de Maria IC, de Andrade CA, Pitombo LM, do Carmo JB, et al. Carbon sequestration and greenhouse gases emissions in soil under sewage sludge residual effects. Scientia Agricola. 2015;72:147-56.

16. European Commission. Closing the loop-An EU action plan for the Circular Economy. 2015.

17. Larsen TA, Udert KM, Lienert J, editors. Source separation and decentralization for wastewater management. London: IWA Publishing; 2013.

18. Trimmer JT, Cusick RD, Guest JS. Amplifying progress toward multiple development goals through resource recovery from sanitation. Environ Sci Technol. 2017:51:10765-76.

19. Harder R, Wielemaker R, Larsen TA, Zeeman G, Öberg G. Recycling nutrients contained in human excreta to agriculture: pathways, processes, and products. Crit Rev Environ Sci Technol. 2019;0:1-49.

20. Haddaway NR, McConville J, Piniewski M. How is the term 'ecotechnology' used in the research literature? A systematic review with thematic synthesis. Ecohydrol Hydrobiol. 2018:18:247-61.

21. Macura B, Piniewski M, Księżniak M, Osuch P, Haddaway NR, Ek F, et al. Effectiveness of ecotechnologies in agriculture for the recovery and reuse of carbon and nutrients in the Baltic and boreo-temperate regions: a systematic map. Environ Evid. 2019;8:39.

22. Haddaway NR, Johannesdottir SL, Piniewski M, Macura B. What ecotechnologies exist for recycling carbon and nutrients from domestic wastewater? A systematic map protocol. Environ Evid. 2019;8:1.

23. Pullin A, Frampton G, Livoreil B, Petrokofsky G. Guidelines and Standards for Evidence Synthesis in Environmental Management. Version 5.0. 2018

24. Haddaway NR, Macura B, Whaley P, Pullin AS. ROSES for systematic review protocols. Version. 2017. https://doi.org/10.6084/m9.figshare.5897269.v4.

25. Harzing AW. Publish or Perish. 2007 http://www.harzing.com/pop.htm.

26. Thomas J, Brunton J, Graziosi S. EPPI-Reviewer 4.0: software for research synthesis. London: Social Science Research Unit, Institute of Education, University of London; 2010.

27. James KL, Randall NP, Haddaway NR. A methodology for systematic mapping in environmental sciences. Environ Evid. 2016;5:7.

28. Haddaway NR, Feierman A, Grainger MJ, Gray CT, Tanriver-Ayder E, Dhaubanjar S, et al. EviAtlas: a tool for visualising evidence synthesis databases. Environ Evid. 2019;8:22.

29. Wiechmann B, Dienemann C, Kabbe C, Brandt S, Vogel I, Roskosch A. Sewage sludge management in Germany. Germany: Umwelt Bundesamt; 2013. https://www.umweltbundesamt.de/sites/default/files/medie n/378/publikationen/sewage_sludge_management_in_germany.pdf.

30. Ministry of the Environment. Inquiry to propose ban on spreading sewage sludge on farmland and a phosphorus recycling requirement. Government Offices of Sweden. 2018. https://www.government.se/press -releases/2018/07/inquiry-to-propose-ban-on-spreading-sewage-sludg e-on-farmland-and-a-phosphorus-recycling-requirement/ Accessed 17 Jul 2019.

31. Macura B, Johannesdottir SL, Piniewski M, Haddaway NR, Kvarnström E. Effectiveness of ecotechnologies for recovery of nitrogen and phosphorus from anaerobic digestate and effectiveness of the recovery products as fertilisers: a systematic review protocol. Environ Evid. 2019;8:29.

\section{Publisher's Note}

Springer Nature remains neutral with regard to jurisdictional claims in published maps and institutional affiliations. 